\title{
A Case Study of How Malay ESL Learners Build Vocabulary Using Multimedia Technology
}

\author{
Nur Sakinah Ahmad Nasaruddin \\ Kulliyyah of Education, \\ International Islamic University Malaysia, \\ Kuala Lumpur, Malaysia \\ sakinahnasaruddin92@gmail.com
}

\author{
Rosemaliza Kamalludeen \\ Kulliyyah of Education, \\ International Islamic University Malaysia, \\ Kuala Lumpur, Malaysia \\ rosemaliza@iium.edu.my
}

\begin{abstract}
This study explored the process of how Malay primary ESL learners build English vocabulary using multimedia technology. With this purpose, students' choices of multimedia technology tools and the reasons behind the choices were investigated. The qualitative approach was employed in this study by conducting semi-structured interviews with three Malay primary school students aged 12 years old from a public school in Kuala Lumpur. The findings revealed that the students chose three main types of multimedia tools namely audio, audio-visual, and video games. The participants revealed three reasons behind their preferences of the multimedia tools which are acquisition of additional information, presence of visuals, and convenience. It was also found that the process of vocabulary-building using the preferred multimedia tools can be organised into four stages namely (i) first encounter, (ii) cognitive dissonance, (iii) establishing equilibrium, and (iv) remembering. The findings suggest English teachers to include multimedia tools in the teaching of vocabulary because it facilitates the process of vocabulary building among students as the words are learned in context and enhanced with visuals.
\end{abstract}

Keywords: Vocabulary learning, multimedia technology, qualitative case study

\section{INTRODUCTION}

In the teaching and learning of any language, vocabulary is the first and essential knowledge to be taught (Murthy, 2020; Bai, 2018). Effective communication is not possible without vocabulary as inadequate vocabulary hinders a language learner to comprehend written texts or convey messages (Kabooha \& Elyas, 2018). When learners have mastered a certain amount of vocabulary, communication becomes possible as people are able to understand each other. They could also express their feelings and thoughts in the language they are communicating (Yunus $\&$ Saifudin, 2019). It was noted that in communication, one might express his thoughts even without correct grammar. However, without vocabulary, one might not be able to express his thoughts effectively (Yunus \& Saifudin, 2019).

Acquiring vocabulary is not an easy task. Mizumoto and Takeuchi (2009) explained that foreign language learners might face more difficulties as their opportunities to use the language 
in social contacts is limited. Nonetheless, for Malaysian students, there are various opportunities to practice English as it is a compulsory subject in school but the command of the language is still a concern due to the lack of vocabulary (Nasir, Ab Manan \& Azizan, 2017; Yunus \& Saifudin, 2019). Furthermore, Jie (2008) asserted that the mother tongue interference is a major obstacle in acquiring a second language.

\section{English Language Learning in Malaysia}

English is Malaysia's second language while Bahasa Melayu is the national language. The history of how the English language came to Malaysia can be traced back to the early 19th century when Malaysia (then Malaya) was colonised by the British Empire for approximately 131 years and this influenced the education system in Malaysia (Darmi \& Peter, 2013). During the British colonisation, schools were divided according to ethnicity whereby Malays went to Malay schools, Chinese went to Chinese schools and Indians went to Indian schools. Every school had a different medium of instruction following the respective mother tongue and the curriculum was based on the country of origin of each ethnicity (Thirusanku \& Yunus, 2014; Darmi \& Peter, 2013; Hanapiah, 2004). After independence, the education system changed and Bahasa Malaysia was made to be the medium of instruction in national schools while the teaching of English remained as it was made as one of the compulsory subjects in schools (Thirusanku \& Yunus, 2014; Darmi \& Peter, 2013; Hanapiah, 2004).

As Malaysia progressed as a developing country, the people realized the importance of English as it is essential in the domains of business, employment, education, media, tourism, law and translation (Thirusanku \& Yunus, 2014; Darmi \& Peter, 2013; Hanapiah, 2004). Realising this, the Ministry of Education announced the separation of the general English paper to two papers - comprehension and writing, in the primary school standardised national examination, Ujian Pencapaian Sekolah Rendah (UPSR) (Abas, 2015).

Despite the efforts of emphasizing the importance of English language in Malaysian education, many students are still poor in terms of their English language proficiency and most of them are due to low levels of vocabulary (Nasir, Ab Manan \& Azizan, 2017; Yunus \& Saifudin, 2019). This will then lead to incompetency to read, write, listen, or speak the language. Specific to the Malay ethnic group, learners' difficulties in mastering English is attributed to the Malay-speaking environment in which learning occurs (Maros, Hua, \& Salehuddin, 2007).

However, leveraging on the current advancements of technology, using multimedia tools is an alternative to help students learn new English vocabulary (Tasa, 2020; Passey, Rogers, Machell, \& McHugh, 2004). This is because multimedia technology incorporates a multi-modal approach which can cater to many types of learners regardless of their passions and interests (Pellerin \& Lavoie, 2019).

\section{The Roles of Multimedia Technology in Vocabulary Teaching and Learning}

Multimedia technology tools are largely used in communication as they enable people to 
connect and share ideas anytime anywhere (Andresen \& Brink, 2013; Clark, 2013). When multimedia technology is applied in communication, it does have an impact on youth in terms of language acquisition. In this study, multimedia tools refer to any computer-related applications that exist in the forms of image, text, audio, video, and animation which are used by primary school students in the process of building new English vocabulary.

In the context of education, Mayer (2014) explains that through a combination of words and pictures, people learn more deeply as opposed to learning from text alone. The cognitive theory of multimedia learning (CTML) by Mayer explains that the human brain's visual/pictorial and auditory/verbal processing channels capacity and duration are maximized when a learner uses two or more forms of media. Verbal communication and printed texts are some examples of multimedia learning through words whereas static images like figures and dynamic ones such as clips and animations are examples of learning through pictures. However, Mayer further asserts, simply putting pictures and words together do not necessarily present better learning materials as they need to be designed following how the human mind works.

Multimedia technology plays a big role in facilitating students to focus and engage in vocabulary learning (Ramezanali \& Faez, 2019). Multimedia technology makes the vocabulary learning of a language easily accessible for students. It is also effective to help them learn a language which includes vocabulary as they are able to read, write, listen and speak the language when communicating using technology tools. Not only that, Ramezanali and Faez further argue that multimedia technology also helps students in organising and remembering the new words that they have learnt.

Despite the roles that multimedia technology tools play in vocabulary teaching and learning, the process of how Malay second language learners build vocabulary with multimedia technology tools are not widely documented since previous studies done were mainly focused on the effects of using multimedia technology in vocabulary learning (Azabdaftari \& Mozaheb, 2012; Clark, 2013; Pinar, 2010; Rodríguez \& Parra, 2005).

\section{Objectives of the Study}

This study was conducted to fill the gap in the research literature on the process of vocabulary learning using multimedia technology tools, particularly on how Malay primary school students use different types of multimedia tools in building their English vocabulary. It is crucial to study this phenomenon as students of the millennial generation are technology natives among whom the use of multimedia tools for learning is a norm. By addressing this problem, English language teachers will be able to design lessons incorporating suitable multimedia tools that will help students expand their vocabulary.

The objectives of the study were to:

1. explore the types of multimedia tools chosen by Malay primary school students in building English vocabulary; 
2. investigate why Malay primary school students choose those multimedia tools in building English vocabulary; and

3. explore how Malay primary school students use multimedia tools in building English vocabulary.

\section{LITERATURE REVIEW}

Various studies presented positive outcomes on vocabulary building when multimedia tools are used in the process of language teaching and learning. Azabdaftari and Mozaheb (2012) concluded that students who were exposed to the multimedia learning app called "Space Repetition System" via mobile devices scored higher in the vocabulary test given at the end of the study as compared to the control group who were not exposed to the tool. Similarly, Kombucha and Elyas (2018) found students who were studying English as a foreign language who were exposed to learning vocabulary via YouTube showed significantly higher scores in the post-test than the control group, indicating significant improvement in vocabulary acquisition. In another study by Rahimi and Allahyari (2019), multimedia-assisted Vocabulary learning strategy (VLS) was found to have a significant impact on vocabulary learning and size when learners who were using multimedia tools improved in their vocabulary acquisition as compared to those who received conventional explicit VLS instruction.

Although Clark (2013) found similar results when foreign language learners in a New York college improved their English vocabulary acquisition through the usage of multimedia tools, the study also revealed that using multimedia tools was insufficient. Exclusive teacher guidance was an important factor in the acquisition of new vocabulary by the learners. Clark explained that the use of technology is only to support teaching and not to replace the roles of teachers. The findings of Rodríguez and Parra's (2005) study on pre-service English language teachers' vocabulary learning corroborated with the findings of Clark (2013). It was reported that with moderation and guidance by instructors, multimedia technology is a good tool to help students in vocabulary learning.

Meanwhile, Pinar (2010) conducted a study on international students at Eastern Michigan University to find out the multimedia technology tools used by the students to improve English language as well as communication skills. It was found that multimedia technology tools like using an electronic dictionary, watching TV with English subtitles and using a chat program had helped the students to improve their English proficiency. According to Pinar, the students claimed that using technology significantly saved their time as they could practice the English language more frequently through the use of computers and the Internet.

Hassan and Abubakr (2015) explored different strategies employed by learners in vocabulary acquisition. It was found that the highest percentage (46\%) of the students claimed that they learnt new vocabulary by watching movies compared to other strategies, followed by listening to English songs and speeches. Hassan and Abubakr added that when the students did not know a word, they guessed the meaning by looking at the context or by looking the word up in the dictionary. 
Usage of multimedia tools has also been reported to facilitate significant outcomes in the learning of languages other than English. Melodie (2014) conducted a case study on students who have average language proficiency in a French class. They were given a French DVD with subtitles to watch and the results indicated that new vocabulary is acquired after every French movie session, while new French vocabulary that was learnt previously was still retained. Comparably, Russian language learners found it more motivating to learn vocabulary through online activities that incorporated multimedia media elements (Kalyuga, Mantai, \& Marrone, 2013). The reason behind the students' motivation to learn new vocabulary was because they were given the freedom to choose the elements they would like to include in their learning. Likewise, Roslan and Sahrir (2020) revealed that students who were learning the Arabic language showed significant improvement in vocabulary acquisition when an image annotation app, ThingLink, was used as an intervention tool. The learners claimed that the multimedia app was easy to use and made understanding new Arabic vocabulary easier compared to traditional learning methods.

Despite the numerous literature reviewed, there is a dearth of research that is done in the context of English vocabulary building among Malaysian students, and more specifically the Malay students using multimedia technology. Therefore, this study was conducted with the hope that it will fill the gap.

\section{METHODOLOGY}

\section{Research Design}

This study incorporated the methodology of a case study whereby the data was collected and analysed qualitatively to suit the goal of the research which is to understand a phenomenon indepth from a real-life perspective (Yin, 2014). The researchers would like to understand how students build vocabulary using multimedia tools during their independent learning sessions particularly outside of a classroom setting.

\section{Participants}

The researchers purposely selected three participants with various factors that were considered to ensure richness in the data (Yin, 2014). As the researchers were interested to explore in-depth on how Malay primary school students build English vocabulary using multimedia technology, the participants sought were primary school students who were using multimedia tools for learning on a regular basis, particularly outside of classroom settings.

The chosen participants were three primary school students from Sekolah Kebangsaan Desa Setapak situated in an urban residential area of Kuala Lumpur. Two of them are male students while one is a female student. All of them are aged 12 years old and in their final year of primary school (Year 6). Their ethnic group is Malay and all of them use multimedia technology tools in building their English vocabulary. In contrast, they have different English proficiency levels. Participant 1 and Participant 3 scored a B grade in their last English test, while Participant 2 obtained a D. In terms of their family background, Participant 1 
communicates with her family mostly in English. Participant 2 speaks Bahasa Melayu with his family while Participant 3 speaks in both Bahasa Melayu and English (mixed).

\section{Interview Protocol}

The interview protocol was designed based on the three research objectives and corresponding research questions. The interview protocol and how it relates to the research objectives as well as research questions can be seen in Table 1 below.

Table 1

Interview Protocol

\begin{tabular}{|c|c|c|}
\hline Research Objective (RO) & Research Question (RQ) & Interview Question \\
\hline $\begin{array}{l}\text { RO1: To explore the types } \\
\text { of multimedia tools } \\
\text { chosen by Malaysian } \\
\text { primary school students in } \\
\text { building } \\
\text { vocabulary; }\end{array}$ & $\begin{array}{l}\text { RQ1: What are the types of } \\
\text { multimedia tools chosen by } \\
\text { Malaysian primary school } \\
\text { students in building English } \\
\text { vocabulary? }\end{array}$ & $\begin{array}{l}\text { 1. Where do you usually encounter } \\
\text { new words? } \\
\text { 2. Could you give example(s) of the } \\
\text { type(s) of multimedia tools that you } \\
\text { like to use in learning new words? } \\
\text { 3. Tell me more about the multimedia } \\
\text { tool(s). } \\
\text { 4. Do you think it is important to } \\
\text { include different types of } \\
\text { multimedia tools in learning new } \\
\text { words? Why? }\end{array}$ \\
\hline
\end{tabular}

RO2: To investigate why Malaysian primary school students choose those multimedia tools in building English
RQ2: Why do Malaysian primary school students choose those multimedia tools in building English vocabulary?
1. Based on your answer in Question 2, why do you like to use the multimedia tool(s) in learning new words?

2. What are the advantages of using the multimedia tools compared to other tools in learning new words?

3. Besides learning new words, what are the things that you can learn from using the multimedia tool(s)?

4. Would you recommend the multimedia tool(s) that you use to learn new words to your friends? Why?

5. Which one do you prefer, learning new words through reading books or using the multimedia tool(s)? Why?

6. Do you want your English teacher to include the multimedia tool(s) while teaching in school? Why? 
Table 1 Continued

\begin{tabular}{|c|c|c|}
\hline Research Objective (RO) & Research Question (RQ) & Interview Question \\
\hline $\begin{array}{l}\text { RO3: To explore how } \\
\text { Malaysian primary school } \\
\text { students use multimedia } \\
\text { tools in building English } \\
\text { vocabulary }\end{array}$ & $\begin{array}{l}\text { RQ3: How do Malaysian } \\
\text { primary school students use } \\
\text { multimedia tools in building } \\
\text { English vocabulary? }\end{array}$ & $\begin{array}{l}\text { 1. How did you start using the } \\
\text { multimedia tool(s) to learn new } \\
\text { words? Describe your experience. } \\
\text { 2. Could you describe the process of } \\
\text { how you learn new words using the } \\
\text { multimedia tool(s)? } \\
\text { 3. Give an example of a word that you } \\
\text { learn while using the multimedia } \\
\text { tool(s). Describe to me or show me } \\
\text { how you understood the word. } \\
\text { 4. How do you remember the words } \\
\text { that you learnt from using the } \\
\text { multimedia tool(s)? } \\
\text { 5. Did you face any problem } \\
\text { understanding a word while using } \\
\text { the multimedia tool? If yes, how } \\
\text { did you overcome it? }\end{array}$ \\
\hline
\end{tabular}

\section{Interview Procedures}

Face-to-face interviews were conducted with each participant separately in their homes, in a relaxed environment so that the participants were able to provide rich information with minimal anxiety. Each interview was conducted with their parents/guardians nearby. They were given the choice whether to have the interview to be conducted in English language or their mother tongue, Bahasa Melayu so that they feel comfortable and natural, similar to a day-to-day conversation. The duration of interviews ranged from 60 to 90 minutes as each participant was probed differently based on how they responded to each question.

\section{Data Analysis}

The data analysis procedure followed Hoyos and Barnes' (2012) guidelines as described in the following paragraphs.

\section{Transcribing}

After every interview session, the recordings were transcribed verbatim. The researchers continued to listen to the recorded interview and edited any information until the transcription is the same as the recording. The transcription was read several times to get a general idea of the interview content.

\section{Coding}

Based on the transcriptions written, a coding process occurred. Firstly, open coding was performed by looking for important keywords and categorising them into main points. Then, axial coding was done by tabulating the information found. The data was arranged in tables for the researchers to identify similar patterns that exist among all data that the participants have provided. This is followed by selective coding when the researchers selected a core category that generalises the findings. 


\section{Triangulation}

Fraenkel, Wallen and Hyun (2015) noted that triangulation is done when 'different methods' or 'types of data' are employed in studying the research phenomenon (p.559) to ensure the richness of information gained from data collection (Patton, 2001). Inthis research, data triangulation was accomplished through member checking where the verbatim transcripts of the individual interviews were shared and discussed with the participants to check for the accuracy of reporting. Since the participants were very young learners, the researchers explained the contents of their verbatim to them in great detail and highlighted the extracted themes and key ideas for their understanding. The participants were asked to verify and confirm that the themes correctly represented their views of and experiences in using multimedia tools to build their respective English vocabulary. The affirmations received from the participants regarding the accuracy of the verbatim transcripts and extracted themes established the credibility and trustworthiness of the study's data and findings.

\section{FINDINGS}

\section{Types of Multimedia Tools Chosen by Students in Building English Vocabulary}

There were three main types of multimedia tools chosen by the participants, namely audiovisual, audio and video games. These tools were mentioned by the participants during the interview sessions.

\section{Audio-visual Tools}

Two participants claimed that they found new English vocabulary when they used audiovisual tools, specifically English movies and English television programmes. According to Participant 1, she found the word "disclosure" while watching an English movie with her mother. She said that the English subtitle was turned on and she knew how it was spelled, but she did not know its meaning.

"I think when I was young, I asked my mom about this word, 'disclosure'. I think it was from a movie...I don't remember the title" (737-741P1)

Likewise, Participant 3 mentioned that he also finds new English words when he watches English movies. Participant 3 said he found the word 'strange' in an English movie that he watched on a subscribed channel..

"Like the word 'strange', actually I found the word in a movie dialogue. I didn't know (the word meaning)." (649P3)

In addition, Participant 3 also watches historical documentaries on the Discovery Channel. He said that he loves to learn about History like the war involving the Germans.

"Like the ones about ancient history...About wars in...where is it?...Like in German and all that"(42-46P3) 


\section{Audio Tools}

The second type of multimedia tools that the students choose in building English vocabulary is audio, namely English radio channels and English songs. Participant 1 listens to English radio channels when she is in the car with her mother, particularly Hitz.fm.

“Erm.. maybe HITZ.fm sometimes. When I go out with my mom."(50-54P1)

As for Participant 3, he listens to English songs on YouTube. An example of an English word that Participant 3 learnt from listening to an English song was 'paw'. The song is entitled 'What Does the Fox Say?' performed by Ylvis. He added that the singer sang the phrase a bit fast that he could not catch what the singer was saying.

"That one (the phrase)...because it's a bit too fast..and also the phrase.."tiny paws","(629P3)

On the contrary, while Participant 2 listens to English songs and sometimes memorises them, he claims to not have learned new English words much from them. He expresses that English songs are too fast for him to actually listen to the words that the singers articulate.

"About songs, I just listen to them, I memorise (the lyrics) but I don't know the meaning (of the song lyrics)" (402P2)

\section{Video Games}

Both male participants, i.e. Participants 2 and 3 said they learned new English words from playing video games. The video games that they are referring to are mission-based games whereby the players need to accomplish a certain mission in order to pass the current level and proceed to the next level.

Participant 2 plays a game called Grand Theft Auto and encountered the word "follow" from the phrase "follow the car" in the game that he was playing. The character that Participant 2 controlled was given a mission to go on a car-chase to catch an enemy.

"Hm ... ha, "follow the car" (the instruction in the mission)." (594P2)

Meanwhile, Participant 3 plays a game called The Last of Us which is a game about a man and a girl surviving from zombie attacks.

"It's about a man and his daughter. They lived in a neighbourhood.. Then, one day.. he was watching the news...in the news, it said the world...aa everybody became zombies (the world was under a zombie attack). So, he wanted to run away from his home.." (276P3)

Both of the games have audio of the characters available as well as English subtitles for players to refer to while playing. 


\section{Reasons Behind the Multimedia Tool Preferences}

It was found that there are three reasons why the students prefer to use the multimedia tools in building English vocabulary. They are acquisition of additional information, presence of visuals, and convenience.

\section{Acquisition of Additional Information}

Participant 3 stated that he learnt a lot of additional information when he learns new vocabulary via audio-visual materials. He explained that when he watches movies, he not only learns new English words but also learns how it is spelled by looking at the English subtitles. He said that sometimes, people learn new words through English movies but they misspell them.

"Like learning new words...and.. .its correct spelling... because sometimes we know the words but we misspell them. Ha that's it." (346P3)

Participant 3 added that when he searched new English words on the Internet, not only did he discover the meaning of the words, he also learned the spelling, pronunciation, synonyms and antonyms. According to him, with a dictionary, he could learn the meaning of the word but could not listen to how it is pronounced.

"If I'm using technology, I get to know a lot of information. Like the word origin, every word must have its origin, how it has its meaning” (368P3)

"Like.. the word "wonderful", every word that we type, it will show its meaning, its synonym, ha something like that." (370P3)

\section{Presence of Visuals}

Participant 1 prefers watching English movies compared to reading books because of the visuals that the movies have.

"Prefer movies than radios (because of the visuals)" (654-657P1)

Participant 3 prefers movies as they are more interesting than dictionaries because of the visuals. He also said that he likes playing games as he learn new English words, entertains himself while playing them, and experiences freedom when he controls his character.

“(I prefer) technology-lah. Because books like dictionaries... they don't have that much pictures (visuals)... Movies are more interesting (because of the visuals)."(514P3)

"I prefer (video) games... in games, I can like...first, I can learn a new word. I also have fun when I play it. Like kids nowadays like (to play) games right ... and ... with games, I can control it (the game character) myself... as for movies, I can only watch (them).." (520P3) 


\section{Convenience}

The two participants with intermediate English proficiency agree that using multimedia tools in learning English vocabulary is convenient. Participant 1 stated that watching movies takes a shorter time than reading a book and highlighted that it is faster to search the meaning of the new words using Google search than finding looking up the physical dictionary.

“Aaa ...reading-I don't know movies are just like.. a short-sentence version from a book."(312P1)

"Aa.. Google (I search word meanings in Google). (I search) Every dictionary from Google”(386-388P1)

“I just use Safari...It's faster."(426P1)

Participant 3 also had the same opinion. He mentioned that it is easier when he searched the meaning on the Internet as opposed to checking the dictionary.

"I'm able to find the words easily than using the dictionary; I have to flip through the pages" (388P3)

\section{Process of Learning New Words Using Multimedia Tools}

The students described how they learned new words using multimedia tools, and the step-bystep process was coded based on their responses. The process is illustrated in Figure 1.

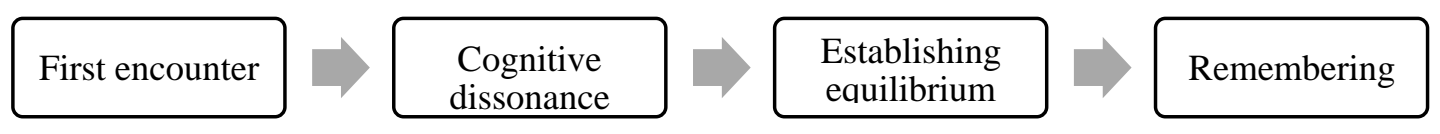

Figure 1: Process of Learning New Words Using Multimedia Tools

\section{First encounter}

Based on the interviews conducted, all students encountered the new English words while they were using the multimedia. The researchers asked each of them to provide an example of the word that they encountered while using the tools. Participant 1 gave an example of a word that she learnt which was 'disclosure' while watching an English movie with her mother. Participant 2 learnt the word "follow" from a game. Participant 3 learnt the word "paw" from listening to an English song. In short, all of the participants experienced their first encounter with new vocabulary while using these multimedia tools without knowing the meaning of the words at first.

\section{Cognitive dissonance (curious to find out)}

It was found that using multimedia tools triggers the participants' curiosity and motivation, thus putting them in a state of cognitive dissonance. Once they encountered the new English word while using the multimedia tools, they were curious and put in effort to find out its meaning. 
Participant 1 said that she always asks her mother first. Her mother either tells her the meaning or asks her to look it up in the dictionary. She then chose to look the word up in an online dictionary.

I asked my mom and basically, she would just say search through the dictionary and I'm like..

"Okay..." (749P1)

Yes. I searched through the dictionary but.... I used the phone (to search the word in an online dictionary). (751-753P1)

In comparison, Participant 2 did not search for the meaning of 'follow' immediately. He said that as he was playing, a text appeared asking the player to 'follow the car'. He did not know what 'follow' meant during that moment but he kept on playing. He made a guess that the game was asking him to chase the car because he said that there was an arrow showing which car to follow and chase.

"It (the game) displays an arrow..(I) must follow the car... until I get to chase it." (596-600P2)

Participant 2 also said that he tried to guess the meaning of words that he found in the textbook. He usually checks back with his teacher to find out whether his guess is correct or otherwise.

"I was just guessing at that time... then, I asked the teacher... It (the guess) was wrong. The correct meaning was these people... they waited a few days, then the firemen came. The firemen aa those people were scared, aa... in a few days, then only the firemen came." (486-490P2)

As for Participant 3, he said that since he could not catch what was being articulated by the singer, he took the initiative to search for the lyrics on the Internet and learned that the word was 'paw' as well as how it is spelled. He then used Google search to find the meaning of the word.

"Then, when I sang the song, I was stuttering, I'd search (the lyrics)..I'd get the words." (590P3)

Each participant has his/her own way to search for the meaning of the words. Each method depends on the participant's preference.

\section{Establishing equilibrium (removing the cognitive dissonance)}

Through searching on the internet, the participants found the meanings of the words they were curious about. Therefore, their state of cognitive dissonance has been reduced or eliminated and they internalize the meanings of the newly found vocabulary. In the case of Participant 2, he found the meaning of the word "follow" from the consequence that occurs after his guessing. The consequence was he passed the mission when he caught the enemy in the car that he was chasing. He also added that when he asked his teacher, his teacher would provide the correct 
answer if his guess was incorrect. Meanwhile, Participant 3 found out the meaning of 'paw' after his Google search via the Internet.

\section{Remembering (adopting a memory strategy through association and real-life application)}

In this final step, the participants adapt a memory strategy through association and real-life application in remembering the new vocabulary learnt via the multimedia tools. All three of them claimed that they were able to remember simple words immediately. Sometimes, if they face difficulties remembering the new word, they would find other definitions that they can understand better which help them to remember.

For instance, Participant 1 was doing her school project and she searched for information via the Internet. When she encountered new English words, she would write them down and search for the meanings later after she has completed her project.

"So, when I want to write something in the web, usually I will get new words from it...So, I just write it and leave it aside so I can do my project first, then I would just search the word..."(384P1)

They also stated that they used the newly encountered words particularly in writing English essays.

"The word 'strange', I used it in an essay before but it was a long time ago. When

I was in Standard Four." (653P3)

In a nutshell, each participant has a distinctive strategy to remember new vocabulary learnt from the multimedia tools. They found a strategy that works for them and used them in their learning.

\section{DISCUSSION}

The findings of this study suggest three main types of multimedia tools chosen by the participants, namely audio-visual, audio, and video games. The audio-visual multimedia tools that the students prefer are English movies and English TV programmes while the audio multimedia tool that they chose in building English vocabulary is radio. The three reasons why they prefer to use the multimedia tools are acquisition of additional information, presence of visuals, and convenience. Various studies have found the advantages of multimedia tools in helping students build vocabulary. One of the advantages of multimedia tools highlighted in this study is convenience as it is faster to search new words using Google than to flip through the dictionary. The international students of Eastern Michigan University seemed to have the same perspective in terms of the convenience present in multimedia tools as the tools saved their time in improving their language (Pinar, 2010). It is common for students to opt for solutions that are convenient and time-saving for them in learning vocabulary. They also get to improve their communication skills when they use multimedia tools like Whatsapp messenger to chat with their friends in English language or when they ask their teacher or mother. This 
absolutely cannot be achieved from flipping the hardcopy dictionary as it only provides oneway communication.

It was also recommended by the participants in this study that multimedia tools should be used by their English teachers when teaching vocabulary in class. The participant who is a beginner in English proficiency also preferred teacher guidance in learning vocabulary because he could not learn English vocabulary effectively on his own.

Zarei and Mahmoudzadeh (2015) investigated the impact of using multimedia gloss, i.e. elements like texts, images, audios, videos or animations that appear on a screen to inform learners about certain words appearing on the screen. It was found that the group facilitated with multimedia gloss performed better in vocabulary learning than the group that was not facilitated with one. Similarly, this study found that multimedia tools like movies and video games help students in building vocabulary as these tools also contain multimedia gloss. Visuals, audio, and English subtitles were present in movies and video games that facilitated the students to learn new vocabulary better than traditionally checking the dictionary. Learning vocabulary enhanced with multimedia gloss is also preferred because the students are presented with more than one medium and they learn the word in context compared to checking the physical dictionary that places the word in isolation and out of context.

\section{How Multimedia Tools are Used in Building English Vocabulary}

The finding of this study proposed the process of learning new words using multimedia tools into four stages: First encounter - Cognitive dissonance - Establishing equilibrium Remembering. All these four stages could be seen in Mayer's Cognitive Theory of Multimedia Learning (Mayer, 2014). According to the theory, there are three memory stores involved in the cognitive process of learning using multimedia which are sensory memory, working memory, and long-term memory. As discussed previously, first encounter occurs when the students find new English words while using the multimedia tools. In comparison with the theory, the multimedia stimuli are presented via the types of multimedia tools chosen by the students. The first stage can be seen in Figure 2 below:

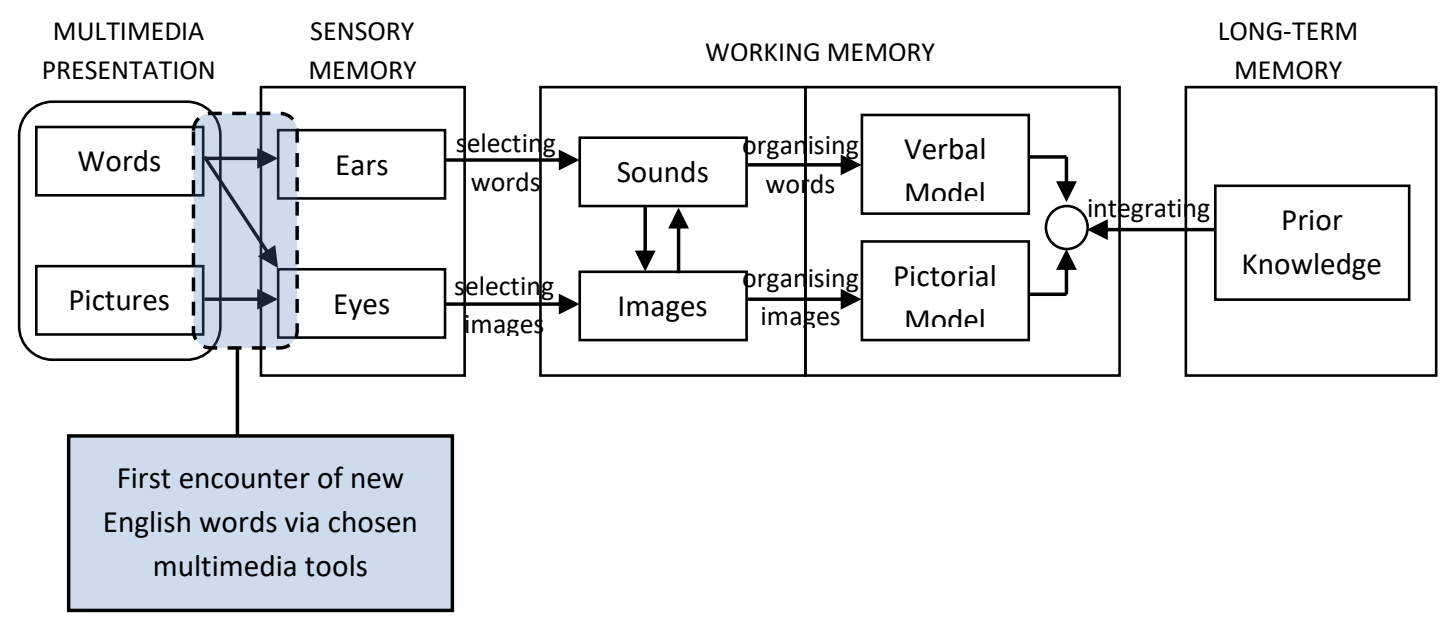

Figure 2: Relationship between First Encounter of New English Words via Chosen Multimedia Tools and Mayer's Cognitive Theory of Multimedia Learning (2014) 
Then, it is followed by the second stage which is 'Cognitive dissonance'. At this stage, the students are curious to find out what is the meaning of the new words that they encountered. In the theory, Mayer (2014) stated that the students' working memory is involved when they select words and organize them to create mental representation which is also known as 'schema'. The process of selecting words, organising them, and creation of mental representation occurs when the participants asked other people, guessed, and searched for the word meaning on the Internet. Figure 3 below shows how this stage is connected to Mayer's Cognitive Theory of Multimedia Learning (2014).

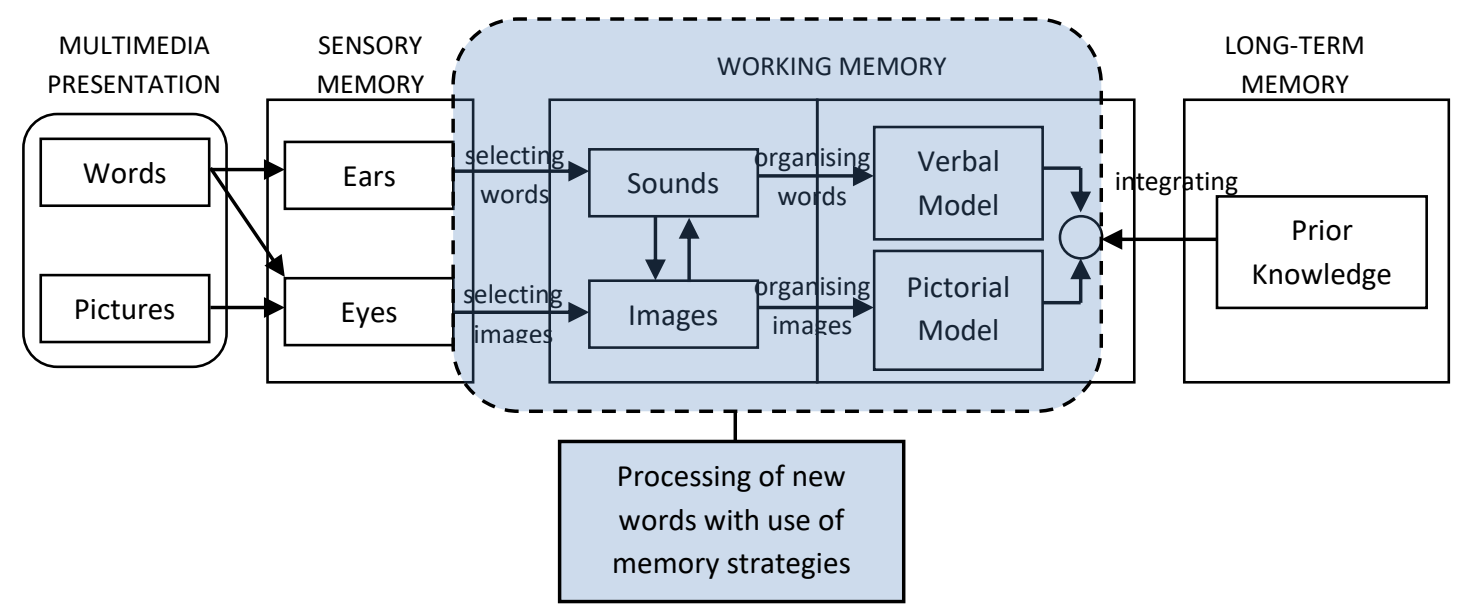

Figure 3: Relationship between Cognitive Dissonance and Establishing Equilibrium Process with Mayer's Cognitive Theory of Multimedia Learning (2014)

From the findings discussed, after they found the word meaning, the participants employed some memory strategies. This shows that the schema created in working memory has been integrated with the students' prior knowledge to form long-term memory (Mayer, 2014). The students' prior knowledge would be Bahasa Melayu terms that they already know for the English words encountered. Hence, when they find out the meaning of new vocabulary, they relate it with its corresponding Bahasa Melayu term. This stage occurs as in Figure 4 below.

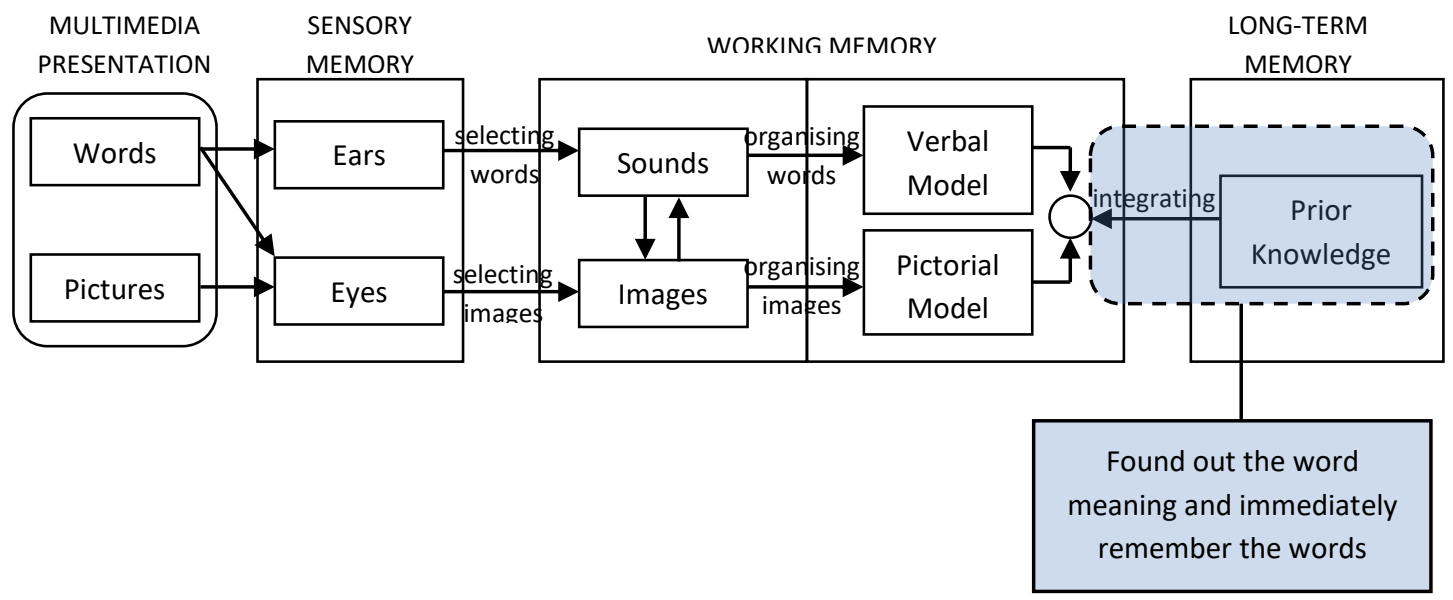

Figure 4: Relationship between Remembering New English Words and Mayer's Cognitive Theory of Multimedia Learning (2014) 


\section{CONCLUSION AND RECOMMENDATIONS}

This study has provided an understanding of how primary school students learn English vocabulary using multimedia technology. The multimedia tools of choice were audio, audiovisual, and video games as these tools provide the students with additional information such as spelling, synonym, and word origins; provides additional visual stimulus; and are convenient e.g. allowing them to search for meanings of words in a shorter time. This study also revealed the process of learning new words using multimedia tools which is organised into four stages: First encounter - Cognitive dissonance - Establishing equilibrium - Remembering. It is hoped that this study will be able to provide a deeper perspective on how primary school students build English vocabulary using multimedia technology, in line with the advancements of technology that has made language learning more interactive, engaging and dynamic.

\section{Recommendations for English Teachers and School Administrators}

As the findings of this study showed that students prefer to utilize multimedia tools in learning vocabulary, teachers should incorporate them in teaching and learning activities. As the students have highlighted, with the combination of multimedia tools as well as teacher-student and peer communication, English vocabulary could be acquired easily since the words are learned in context and enhanced with visuals. In line with the current trends in online learning, teachers may include assignments such as reading multimedia-enhanced e-books, video watching, and listening to podcasts, after which they will come up with reflective writing that will give avenues for students to build vocabulary. Students nowadays are using multimedia tools for entertainment and communication. They will feel excited to learn English vocabulary and might even try to explore on their own without the need to wait for the next lesson. English teachers however must be careful in choosing the multimedia tools. It is to ensure that the contents are suitable and appropriate for students to learn. The tools are not meant to replace the teachers completely, rather to facilitate the vocabulary building process.

School administrators need to play a role in providing the best tools to enhance language learning. Teachers need to be provided with adequate facilities and infrastructure so that the teaching and learning process will be more efficient through the usage of multimedia tools.

School administrators could conduct activities and competitions that incorporate multimedia tools to motivate students to use English language. For example, setting up a school podcast channel, YouTube channel, or social media account to relay content learned. Another example would be to conduct competitions like a cooking show, news anchoring, educational music video and social media awareness campaign. All of these utilise multimedia tools and the students will be able to build and practice English vocabulary in context.

In short, multimedia tools are essential in vocabulary building. Therefore, it is imperative that teachers adopt various tools and incorporate them into the delivery of lessons to ensure that students are kept motivated to master the English language despite challenges in learning English as a second language. 


\section{REFERENCES}

Abas, A. (2015, September 28). UPSR: Two English papers in 2016. New Straits Times, Retrieved from https://www.nst.com.my/news/2015/09/upsr-two-english-papers-2016

Andresen, B. B., \& Brink, K. V. D. (2013). Multimedia in Education Curriculum. Moscow, Russian Federation: UNESCO Institute for Information Technologies in Education. Retrieved from https://iite.unesco.org/pics/publications/en/files/3214723.pdf

Azabdaftari, B., \& Mozaheb, M. A. (2012). Comparing vocabulary learning of EFL learners by using two different strategies: Mobile learning vs. multiple chcards. The EUROCALL Review, 20(2), 47-59. Retrieved from https://doi.org/10.4995/eurocall.2012.11377

Bai, Z. (2018). An Analysis of English Vocabulary Learning Strategies. Journal of Language Teaching and Research, 9(4), 853-859. Retrieved from http://www.academy publication.com/ojs/index.php/jltr/article/view/jltr0904849855/1561

Clark, M. (2013). The use of technology to support vocabulary development of English language learners. (Master's thesis, St. John Fisher College, New York, USA). Retrieved from https://fisherpub.sjfc.edu/education_ETD_masters/238/

Darmi, R., \& Albion, P. (2013, July 3-4). English language in Malaysian education system: Its existence and implication [Paper presentation]. 3rd Malaysian Postgraduate Conference (MPC 2013), Sydney, New South Wales, Australia. Retrieved from https://www.researchgate.net/publication/279867616

Fraenkel, J. R., Wallen, N. E. \& Hyun, H. H. (2015). How to Design and Evaluate Research in Education ( $8^{\text {th }}$ ed.). New York: McGraw-Hill

Hanapiah, M. F. (2004). English language and the language of development: A Malaysian perspective. Jurnal Kemanusiaan, (3),107-120.

Hassan, Z. M., \& Abubakr, S. N. (2015). English vocabulary learning strategies by EFL learners at University of Sulaimani: A case study, International Journal on Studies in English Language and Literature, 3(3), 23-29. Retrieved from https://www.academia.edu /35249616/English_Vocabulary_Learning_Strategies_by_EFL_Learners_at_University _of_Sulaimani_A_Case_Study

Hoyos, M. de, \& Barnes, S.-A. (2012). Analysing interview data [PowerPoint slides]. Retrieved from https://warwick.ac.uk/fac/cross_fac/esrcdtc/coretrainingmodules/quals/ analysing_ interview_data_1_-_w6.pdf

Jie, X. (2008). Error theories and second language acquisition. US-China Foreign Language, $6(1), 35-42$.

Kalyuga, M., Mantai, L., \& Marrone, M. (2013). Efficient Vocabulary Learning Through Online Activities. Procedia - Social and Behavioral Sciences, 83, 35-38. Retrieved from https://doi.org/10.1016/j.sbspro.2013.06.007

Kabooha, R., \& Elyas, T. (2018). The effects of YouTube in multimedia instruction for vocabulary learning: Perceptions of EFL students and teachers. English Language Teaching, 11(2), 72-81. Retrieved from https://files.eric.ed.gov/fulltext/EJ1166511.pdf 
Mahmood, H. (2014). Civics and citizenship education in Malaysia: The voice of micro policy enactors. (Doctoral Thesis, Cardiff University). Retrieved from http://orca.cf.ac. uk/id/eprint/69576.

Maros, M., Hua, T. K., \& Salehuddin, K. (2007). Interference in learning English: Grammatical errors in essay writing among rural Malay secondary school students in Malaysia. Jurnal e-Bangi, 2(2), 1-15.

Mayer, R. (2014). The Cambridge handbook of multimedia learning (2nd ed.). Cambridge: Cambridge University Press.

Mizumoto, A., \& Takeuchi, O. (2009). Examining the effectiveness of explicit instruction of vocabulary learning strategies with Japanese EFL university students. Language Teaching Research, 13, 425-449.

Mohd Nasir, N.F.W., Ab Manan, N.A. \& Azizan, N. (2017). Examining the relationship between vocabulary knowledge and general English language proficiency. ESTEEM Journal of Social Sciences and Humanities 1, 15-22. Retrieved from http://ir.uitm .edu.my/id/eprint/29794/

Muniandy, S. (2015, November 26). Poor command, fewer career opportunities. New Straits Times Retrieved from https://www.nst.com.my/news/2015/11/113866/poor-commandfewer-career-opportunities

Murthy, N. S. R. (2020). Techniques for Teaching/Learning Vocabulary: A Brief Study. Journal for Research Scholars and Professionals of English Language Teaching, 19(4). Retrieved from https://papers.ssrn.com/sol3/papers.cfm?abstract_id=3630162

Roslan, N. N. A. ., \& Sahrir, M. S. . (2020). The Effectiveness of ThingLink in Teaching New Vocabulary to Non-Native Beginners of the Arabic Language. IIUM Journal of Educational Studies, 8(1), 32-52. Retrieved from https://journals.iium.edu .my/ijes/index.php/iejs/article/view/274

Passey, D., Rogers, C. G., Machell, J., \& McHugh, G. (2004). The motivational effect of ICT on pupils. DfES Publications, Research R. Retrieved from http://eprints.lancs.ac. $\mathrm{uk} / 13386 /$

Patton, M. (2001). Qualitative Evaluation and Research Methods (2 $2^{\text {nd }}$ ed.). Thousand oaks, CA:Sage Publications.

Pellerin, M. \& Lavoie, C. (2019). Multimodal and multisensory approach to teaching and learning vocabulary [Paper presentation]. International Conference on Research in Education, Sydney, Barcelona, Spain. Retrieved from https://www.doi.org/10.33422 /icreconf.2019.04.224

Pinar, K.-A. (2010). Using educational technology tools to improve language and communication skills of ESL students, Novitas-ROYAL (Research on Youth and Language)4(2), 225-241. Retrieved from https://dphu.org/uploads/attachements /books/books_2631_0.pdf

Rahimi, M. \& Allahyari, A. (2019). Effects of multimedia learning combined with strategybased instruction on vocabulary learning and strategy use. SAGE Open, 1-14. doi: $10.1177 / 215824401984408$ 
Ramezanali, N., \& Faez, F. (2019). Vocabulary learning and retention through multimedia glossing. Language Learning \& Technology, 23(2), 105-124. Retrieved from https://doi.org/10125/44685

Rodríguez, A. R. R., \& Parra, M. E. G. (2005). The influence of ICTs in vocabulary learning: an empirical study, Porta Linguarum 4, 87-107. Retrieved from https://www.researchgate.net/.publication/28178442_The_influence_of_ICTs_in_ vocabulary_learning_an_empirical_study

Tasa, S.S. (2020). The impact of technology on enhancing adult EFL learner vocabulary (Master's thesis, ÇAĞ University, Mersin Province, Turkey). Retrieved from https://hdl.handle.net /20.500.12507/1460

Thirusanku, J. \& Yunus, M. (2014). Status of English in Malaysia. Asian Social Science, 10(14), 254-260. Retrieved from https://doi.org/ 10.5539/ass.v10n14p254

Yin, R. K. (2014). Case study research: Design and methods (5th ed.). Thousand Oaks, CA: SAGE.

Yunus, K \& Saifudin, M.S. (2019). Vocabulary learning strategies among English as second language learners. Journal of Qualitative Social Sciences, 1(1), 12-19. Retrieved from http://asianscholarsnetwork.org/journals/index.php/jqss/article/view/15/11

Zarei, A. A., \& Mahmoudzadeh, P. O. (2015). Multimedia Glosses in L2 vocabulary Learning and Reading Comprehension. Statewide Agricultural Land Use Baseline 2015, 1. Retrieved from https://doi.org/10.1017/CBO9781107415324.004 